\title{
Generation of motion sequences for thermal load of machine tools
}

\author{
Hubert Höfer ${ }^{1}$ (D) Hajo Wiemer ${ }^{1}$
}

Received: 14 June 2016/ Accepted: 23 November 2016/Published online: 1 December 2016

(C) The Author(s) 2016. This article is published with open access at Springerlink.com

\begin{abstract}
An increase in the installed driving power is a typical method to improve machine tools' productivity. However, this measure also results in higher dissipation losses, which, in turn, cause an increase in thermally induced displacements on machine tools. To maintain or even increase machining accuracy, techniques that can compensate and correct thermally induced displacements have been engineered. To evaluate their effectiveness, a test workpiece and a motion sequence for the machine axes were developed, by means of which the machine tool can be warmed up in a defined manner to its thermal steady state. The paper introduces the conceptual design of the motion sequence and shows an example of its application.
\end{abstract}

Keywords Machine tool · Thermal error - Test piece . Evaluation strategies $\cdot$ Measurement

\section{Introduction}

The Collaborative Research Centre (CRC) "Transregio 96" focuses on the exploration and implementation of correction and compensation solutions that influence the thermoelastic behavior of machine tools to enable high accuracy machining in the context of future demands for energy-efficient manufacturing.

Hubert Höfer

hubert.hoefer@tu-dresden.de

Hajo Wiemer

hajo.wiemer@tu-dresden.de

1 Institut für Werkzeugmaschinen und Steuerungstechnik, TU Dresden, 01062 Dresden, Germany
A test workpiece was designed in order to verify the efficiency of different approaches in representing thermally induced machine tool displacements. Another purpose of the test workpiece is to make the different machine tools and solution concepts commensurable in terms of their thermal behavior. For this purpose, a commensurable thermal machine load is required. The machine tool is warmed up without any machining, just by accelerating and decelerating the feed axes and the main spindle. The predefined geometrical elements on the test workpiece are finished in the time between the sequences of accelerating. Since the displacements to be represented on the test workpiece amount to only a few micrometers, surveying and analysing the test workpieces are therefore also very challenging. For this reason, the test process elaborated within the scope of the CRC "Transregio 96" includes both the machining of the test workpiece and the strategy of warming up the machine tool, as well as the measurement and analysis. This paper focuses specially on the strategy to warm up the machine tool.

\section{State of the art}

The degree to which thermal behavior affects machining accuracy at the machine tool's active point-the tool center point (TCP) — can be recorded by direct or indirect measurements. The direct measurements are based on the requirements of the ISO 230-3 [3], ISO 10791-10 [4] and ISO 13041-8 [5]. The standards describe the experimental procedure and the technical evaluation of the measurement results. The TCP displacements are recorded relatively between the main spindle and the machine table by means of contactless displacement transducers. At the same time, the temperatures are recorded at several positions of the 
machine tool. Indirect measurements with test workpiece lead to very illustrative statements about the working accuracy of the machine tool. In contrast to direct measurements the machine errors and process influences act summarily on the results at the test workpiece. Indirect measurements with test workpiece illustrate the overall function of the machine tool or are used for the indirect determination of individual characteristics. There are test workpieces according to VDI 2851 sheet no. 3 [9] (refinement of the standard NAS 913), according to ISO 10791-7 [10] and VDI 3443 [11] for NC milling machines. Standardized test workpieces are available for the geometric-motion, static and dynamic accuracy behavior and especially for machine tools intended for five-axis machine tools with high speed cutting [12-14]. Recent activities in the research put the focus on the improvement of the test workpiece for evaluate the performance of five-axis milling machines according to ISO 10791-7. In [15] a cone frustrum test pieces according ISO 10791-7 were milled at four different positions on a five-axis machining center and the results were compared with kinematic simulations. It was shown by simulation and machining, that the accuracy of the test-pieces depends not only on the geometric characteristics of the machine tool, but also on the position and orientation of the test-piece. Su and Wang [16] introduces a new machining test standard that has been proposed for testing the accuracy of five-axis machine tools using an $\mathrm{S}$-shaped test piece. The advantages of the S-shaped test method are analyzed and demonstrated. The focus in [17] is on the repeatability and functionality of the cone frustum acceptance test presented in the draft standard 2012, ISO 10791-7. This work proposes to use instead of standard cone frustum two or more conical surfaces. Westermann et al. [18] has been developed a test workpiece to assess the energy efficiency of machine tools. In the field of test workpieces for thermal induced displacements existing individual investigations, but no known standardized test workpieces. In [19] a test workpiece is used to show the difference of measurable thermal induced errors with direct and indirect measurements systems for axes with ball screw drives. In [20] a test workpiece was developed to show the influence of thermal deformation on error motions of rotary axes in five-axis machine tools. Therefore more than one workpiece is required. And in [21] a test workpiece is shown for evaluation of thermally induced deviations of rotary tables on five-axis machine tools. For investigations of the thermal displacements with test workpieces, the recommendation in literature [8] is as follows according to VDI 2851: "To record thermal machine displacements, several test workpieces are machined during the warming up stage at intervals of approximately $30 \mathrm{~min}$. In the meantime, the machine is loaded with production parts. It has to be considered that a special tool, which is not employed for production parts, is employed for the test workpieces."

The warming up of the machine tool for direct and indirect measurements are based on acceleration phases and phases with constant speed of the feed axes and the main spindle. The dissipation power generated here leads to the heating of the machine tool. Guidelines for warming up are defined in DIN V 8602 [6] and ISO 230-3 [3]. DIN V 8602 describes two ways of warming up the machine with the main spindle. Either a constant rotational speed with $75 \%$ of the maximum speed over $480 \mathrm{~min}$ or with a rotational speed range over $450 \mathrm{~min}$ (Fig. 1). In ISO 230-3 are defined three tests for the determination of thermal effects on machine tools: an environmental temperature variation error (ETVE) test; a test for thermal distortion caused by rotating spindles and a test for thermal distortion caused by moving linear axes. For main spindle the load can be carried out with constant rotational speed as percentage of the maximum rotational speed with a speed range over $240 \mathrm{~min}$ (Fig. 2).

The duration of each rotational speed level and the breaks in [3] can vary between 2 and 30 min according the different loads. A shortening or extending the measurement period is allowed until the distortion change during the last $60 \mathrm{~min}$ is $<15 \%$ of the maximum distortion registered during the first hour of the test.

The loading of the feed axes is performed by accelerating, driving at a constant speed and deceleration. The feed rate is expressed as a percentage of the maximum feed rate. A separate range for the speed does not exist. The measurement of thermally induced deformation in accordance with DIN 230-3 is performed at intervals of $5 \mathrm{~min}$ during the entire load duration and the subsequent cooling phase. In practice the rotational speed range according to DIN V 8602 is also used for the loading of the feed axes [7]. The guidelines of standards are based on the maximum values of rotation speed and feed rate. The generated dissipation power depends on the utilized drive power in phases of acceleration and constant drive in the warm-upcycle. To emphasize thermally induced errors compared to

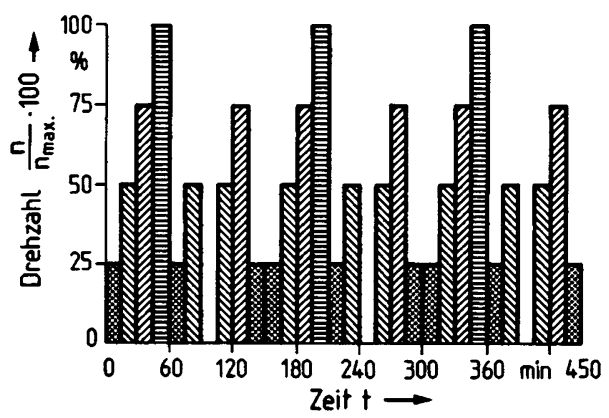

Fig. 1 Rotational speed range for warming up a machine in DIN V 8602 [6] 


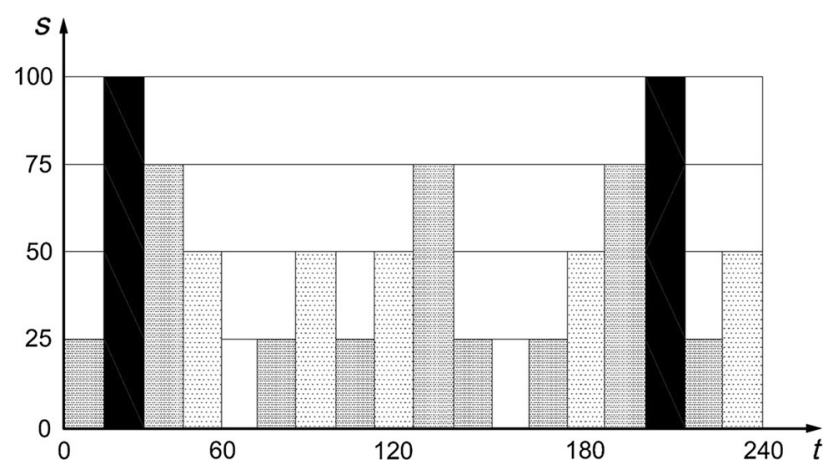

Fig. 2 Rotation speed range for warming up a machine in ISO 230-3 [3]

other errors, it is necessary to generate sufficiently high power dissipation. Therefore test cycles with several acceleration phases for the spindle and the axes are used.

\section{Engineering of the test workpiece}

To obtain a representation of the thermally induced displacements, the thermal behavior of machine tool has to be recorded over a period of several hours. Since this is impossible by means of the test workpieces above, a suitable test workpiece was engineered within the CRC "Transregio 96". The basic principle of the thermal test workpiece is introduced in [1] and only summarized here. The test workpiece (Fig. 3) is designed with shape elements- to be finished at intervals - for each axial direction.

At the beginning of the test procedure, the machine tool is thermally balanced with the environment and the reference surfaces for the shape elements, as well as the first shape element are milled. The machine tool is warmed up to its steady state with a special motion sequence. This is achieved by accelerating and decelerating of one or more feed axes and the main spindle. The motion sequence is interrupted at predefined time intervals. Additional shape elements are milled into the test workpiece, whereby the thermally displaced TCP is in action. The test workpiece is measured after manufacturing, and the displacement-time curves are determined. The test workpiece is very compact. Therefore it maps only translational displacements in a certain area of the machine tool's workspace. In the manufacture of molded elements in the $\mathrm{x}$ - and $\mathrm{y}$-direction, a possible reduction of the tool diameter as a result of wear goes directly into the mapped geometry errors. A wear on the tool can reach a relevant magnitude for these investigations [2]. Therefore, the actual diameter of the tool during the production will also be displayed five times in the test workpiece (Fig. 3). Thus, a wear are recognized and included in the results.

\section{Generation of motion sequences}

\subsection{Requirements for the motion sequences}

The comparative evaluation of the investigated correction and compensation methods requires for all machines the same test workpiece and a comparable motion sequence to warm up the machine. The test cycle should ensure the comparability of studies on various machines. So it's not designed for the realization of the thermal load of real milling processes. Following requirements were considered for the motion sequence:

- During motion sequence is no cutting.

- Generation of significant thermally induced displacements by phases with high acceleration.

- Basis for motion sequence are the drive powers, not the maximum values of rotational speed and feed rate as in the standards.
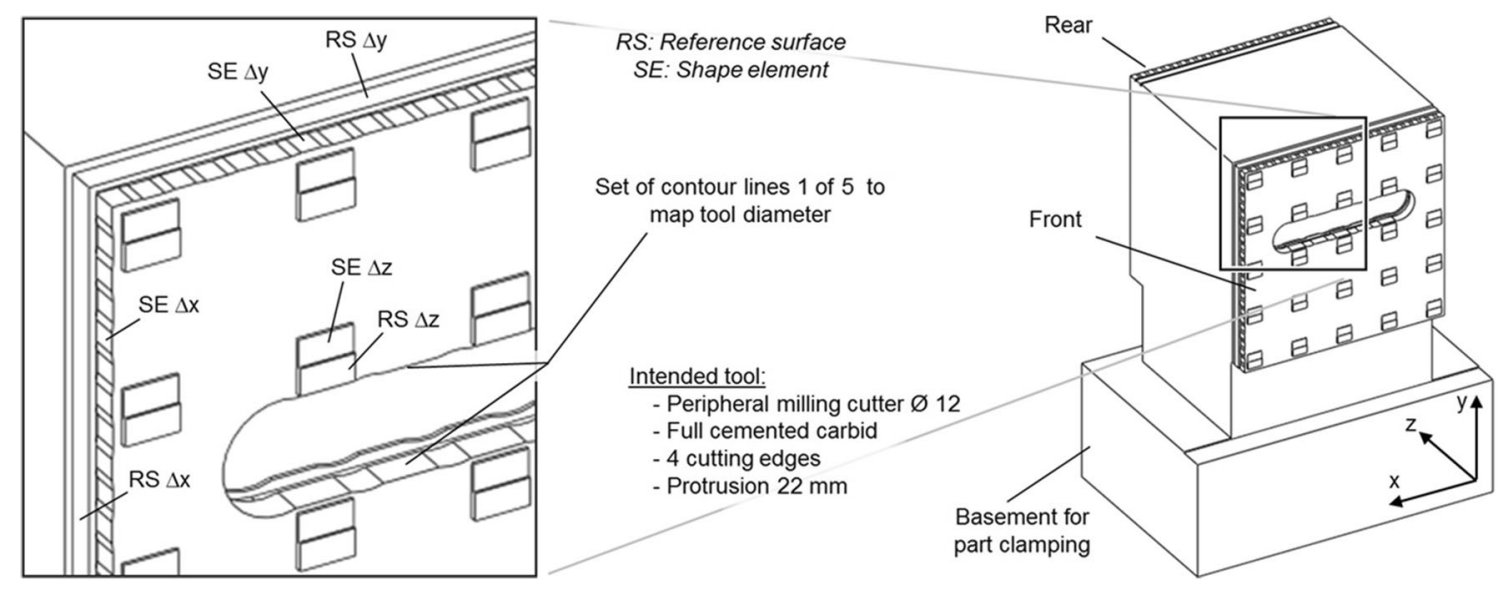

Fig. 3 Design of the thermal test workpiece [1] 
- Transferability of the motion sequence to various machines in order to minimize the time and cost to program the motion sequences.

\subsection{Strategy to determine the motion sequence}

The motion sequence to warm up the machine tool consists of one or several motion cycles. The general method to determine the motion sequence is summarized in Fig. 4.

The structure of the motion cycle is based on decisions and agreements taken according to the technical data of the machine tool. It includes specifications for the motion profile and the position of movements in machine's workspace. The motion axis parameters and the rotational speed mode are set based on the machine tools' data.

\subsubsection{Structure of the motion cycle}

The methodology is demonstrated for a motion sequence which has already been used for the manufacturing of several test workpieces. In this example each axis in the motion cycle is moved at the same frequency. Furthermore, for each axis, the same feed rate is assumed and the same proportion of the axis travel is used. The axis motions are carried out symmetrically to the table centre. The associated motion cycle is illustrated in Fig. 5.

The characteristics of this example are specified below:

- Utilisation of $70 \%$ of the axis travel for each axis symmetrically to the table centre.
- Every axis is moved four times in one motion cycle.

- The motion cycle can be realized with parameters in cutting feed or in rapid traverse.

- In cutting feed each axis motions consists of accelerating, constant speed at $30 \%$ of the travel, and decelerating.

- In rapid traverse, each axis motions consist of maximum acceleration, constant speed and maximum deceleration in four steps.

In the example (Fig. 5), the zone around the test workpiece is kept free to avoid collision. It based on milling processes which are realized mainly in the center of the workspace. This is associated with a heat input in the center of the workspace, here $70 \%$ of the travel. In the simplest case each of the three translational axes feed is moved equally often. The axes are moved with a percentage of their maximum driving performance. A real thermal load can be approximated by the number of simultaneous axes and their used power.

\subsubsection{Machine tool data}

These data involve axis travels, nominal power values, maximal acceleration and speed, as well as the moments or inertia of the moved subassemblies reduced to the drive axes. It takes considerable time and expense to determine the machine tool's required parameters of inertia, and often they can only be provided by the manufacturer. If it is impossible to obtain the parameters, then one can carry out a measurement and draw conclusions regarding substitute

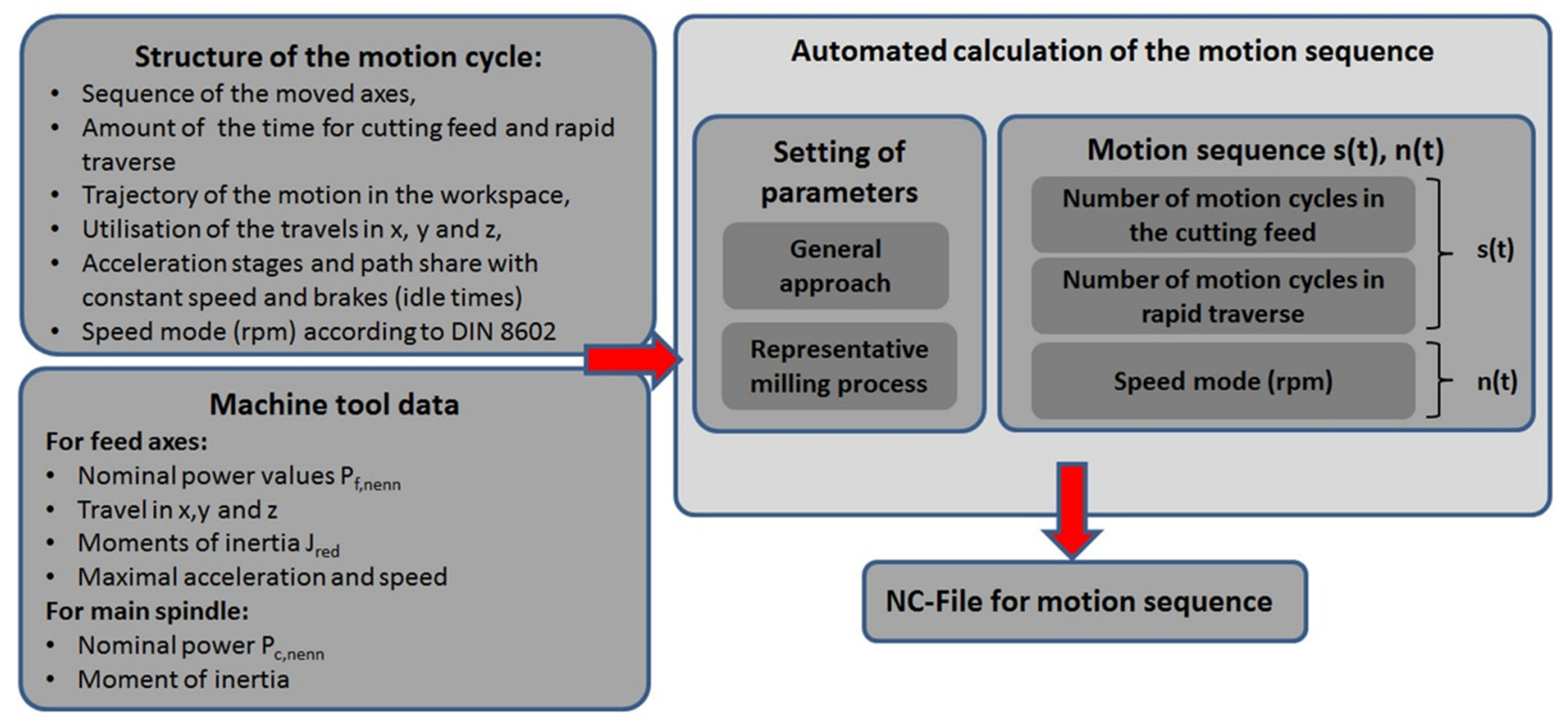

Fig. 4 Algorithm to generate the NC program for the motion sequence 

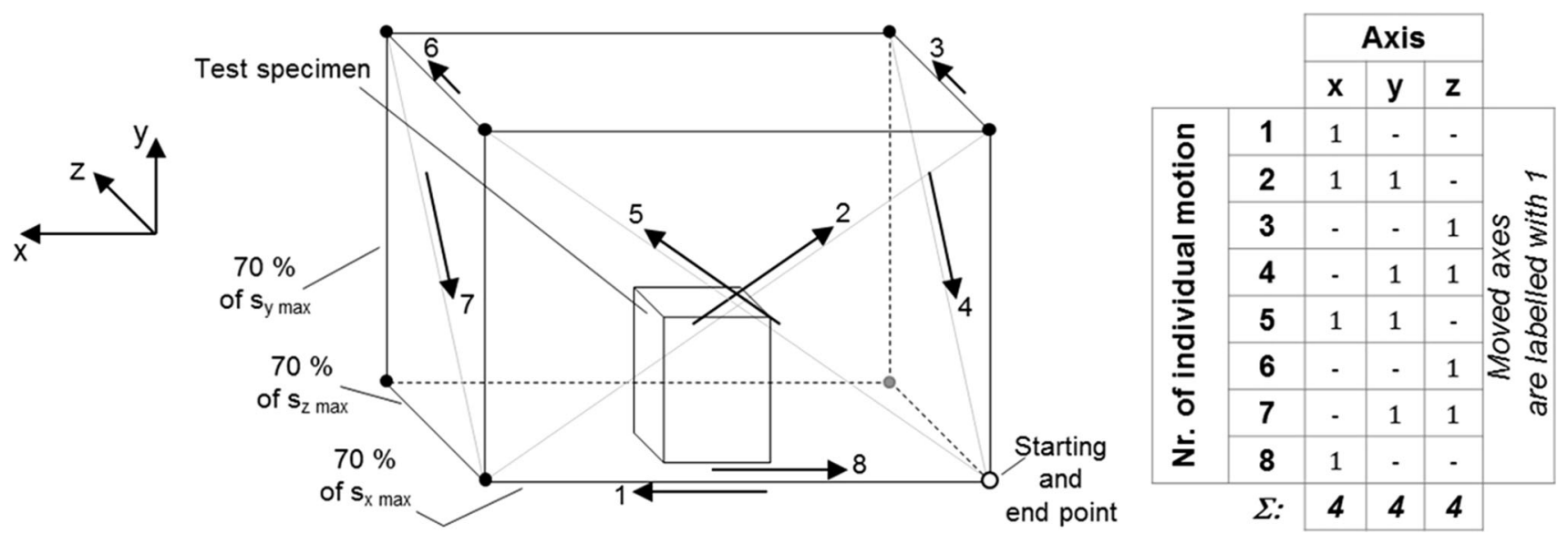

Fig. 5 Working principle of the motion cycle to warm up the machine tool

variables from the electrical energy consumed for a known motion. To set parameters for the motions, the nominal power values of the feed drives, the axis travels, and the moments of inertia reduced to the drive axis, as well as maximal acceleration and speed values of the axes, are required.

\subsubsection{Automated calculation of the motion sequence}

The motion sequence is calculated in an automated manner by means of MATLAB software. In this process, it is first necessary to calculate the acceleration and speed values in the motion cycle. The acceleration values depend on the power data, which are a percentage of the nominal power values of the feed drives and the main spindle. Depending on the percentage the thermal load of the machine and associated power dissipation generate thermal errors that can be measured in a significant way. In standards a test cycle is specified by a percentage of the rotational speed of spindle, which is held constant. So the power dissipation follows only through friction. So the power dissipation by the spindle is low. The movement of a feed axis is also specified by a percentage of the feed rate. This means maximum acceleration, constant speed with predefined value and maximum deceleration. At higher speed follows a longer acceleration phase and thus power dissipation. Thus, the phases of acceleration have of great importance for the power dissipation during an axis or spindle movement. For significant thermal deviation for mapping on the test workpiece, it is obvious to integrate several acceleration phases in the axes movements, and thus generate higher power dissipation. Therefore the axes movements will specified in contrast to the standards by a percentage of the nominal power values of the feed drives and the main spindle. This value is understood as the average power of an axis movement. During the acceleration phases the value is higher, at constant speed it is significantly lower.

\subsection{Values of accelerations for the motion cycles}

The motion sequence is, in principle, the stringing together of several motion cycles. The parameters of each motion cycle can be set using the acceleration and speed data in the cutting feed or rapid traverse. As a result, a path-time curve and a speed-time diagram are obtained, which are intended to create a machine-specific NC program for the motion sequence. The averaged cutting power $\mathrm{P}_{c}$ serves as the basis for the calculation of the angular acceleration of the main spindle. The averaged feed power $\mathrm{P}_{\mathrm{f}}$ is the base to compute the axis accelerations. Within the motion cycle, the highest power is used in the acceleration and braking phases. During the phase with constant speed the friction power is assumed to be negligible in contrast to the power in acceleration phases. Since the travel $x$ of the feed axes is only utilised in a spatial way by the factor $k$ and there is a constant speed on the path ratio $l$ of the travel $\mathrm{x}$, the averaged feed power $\mathrm{P}_{\mathrm{f}}$ is transformed into the acceleration power $P_{m}$ (1). Figure 6 shows the context:

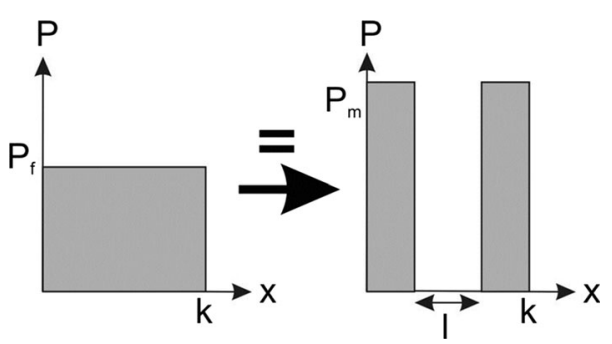

Fig. 6 Context between averaged feed power $P_{f}$ and averaged power $P_{m}$ 


$$
P_{m}=P_{f} \cdot \frac{k}{k-l}
$$

For linear and rotatory axes follows different ways to calculate the axis accelerations.

\subsubsection{Linear feed axis with screw drive}

The constant acceleration of a motion at an averaged power $P_{m}$ is calculated for the example of a translational feed axis with a ball screw of the pitch $h$ and a directly coupled servo motor according to Eq. (2).

$a=\frac{h}{\pi} \cdot \sqrt{\frac{P_{m}}{2 \cdot t_{b} \cdot J_{\text {red,trans }, S p}}}$

$J_{\text {red,trans,Sp }}$ is the moment of inertia for a linear feed axis reduced to the spindle, $t_{b}$ the acceleration time and $a$ the acceleration to be found. The acceleration path $x_{b}$ can be described with (3) and depending on the axis travel $\mathrm{x}$ (4):

$x_{b}=\frac{a}{2} \cdot t_{b}^{2}$

$x_{b}=\frac{x \cdot(k-l)}{2}$

So the feed axis acceleration $a$ can be specified with (1)(4) as a function of the feed power $P_{f}$ :

$a=\sqrt[3]{\left(\frac{h^{2} \cdot P_{f} \cdot k}{2 \cdot \pi^{2} \cdot J_{\text {red,trans }, \text { Sp }} \cdot \sqrt{x \cdot(k-l)} \cdot(k-l)}\right)^{2}}$

The motion in the rapid traverse is based on the maximal acceleration $a_{\max }$ at maximal speed $v_{\max }$. Both values can be taken from the machine tool manufacturers' catalogues. According to (2), the feed power $P_{e i l}$ for rapid traverse is accordingly:

$P_{\text {eil }}=\frac{2 \cdot \pi^{2} \cdot \mathrm{a}_{\max } \cdot \mathrm{v}_{\max } \cdot \mathrm{J}_{\mathrm{red}}}{h^{2}}$

\subsubsection{Linear feed axis with direct drive}

For feed axes with direct drive, the constant acceleration is calculated according equation:

$a=\sqrt{\frac{2 \cdot P_{m}}{m_{\text {trans }} \cdot t_{b}}}$

With $m_{\text {trans }}$ as the translational moved mass and Eqs. (1), (3) and (4) follows the axis acceleration $a$ for direct drive linear axes:

$a=\sqrt[3]{\left(\frac{2 \cdot P_{f} \cdot k}{m_{\text {trans }} \cdot \sqrt{x \cdot(k-l)} \cdot(k-l)}\right)^{2}}$

\subsubsection{Rotary and swivelling feed axes}

For rotary and swivelling feed axes the following relation is valid for the averaged power $\mathrm{P}_{\mathrm{m}}$ :

$P_{m}=\frac{\ddot{\varphi}^{2}}{2} \cdot t_{b} \cdot J_{r e d, r o t}$

The relationship for the angle $\varphi_{b}$ to accelerate a swivelling or rotary axis is as equation:

$\varphi_{b}=\frac{\ddot{\varphi}}{2} \cdot t_{b}^{2}=\frac{(k-l) \cdot \varphi_{g e s}}{2}$

The whole motion consists of an acceleration and deceleration stage. Similar to the linear axis $k$ denotes the proportion of the angle, which is utilised and $l$ the share of angle $\varphi_{\text {ges }}$ with constant angular speed. Thus, the angular acceleration is a function of feed power $P_{f}$, the moment of inertia $J_{\text {red,rot }}$ for a rotatory feed axis reduced to the spindle and the parameters $l$ an $k$ :

$\ddot{\varphi}=\sqrt[3]{\left(\frac{2 \cdot P_{f}}{J_{\text {red,rot }} \cdot(k-l) \cdot \sqrt{\varphi_{g e s} \cdot(k-l)}}\right)^{2}}$

\subsubsection{Main spindle}

The time curves of the spindle speeds are oriented at the speed stages according to DIN V 8602 part 1 . In the speed stages according to Fig. 7 the averaged speed values $\bar{n}$ are each available for a time interval of $1 \mathrm{~min}$. With the nine speed segments in Fig. 7, follows a mean rotational speed $\overline{n_{z y k}}=0.6055 \cdot n_{\max }$ as a base to calculate the averaged angular acceleration. For axis motions in rapid traverse, it is assumed that no heat enters into the structure from the main spindle. This assumption is justified by the fact that the rapid traverse motions are mostly connected with a tool

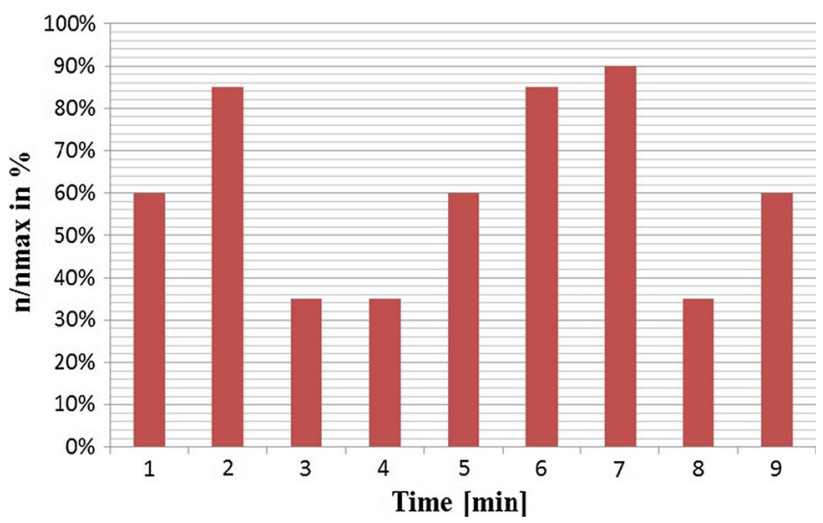

Fig. 7 Rotational speed mode according to DIN V 8602 
change or an approach to a contour that is at a great distance, whereas the main spindle is in a standstill position.

Thereby the angular acceleration for the main spindle follows from the required cutting power of the milling process $\mathrm{P}_{\mathrm{c}}$, the proportion of rapid movement of the total movement, represented by a factor of e, the averaged rotational speed $\overline{n_{z y k}}$ and the reduced moment of inertia $\mathrm{J}_{\mathrm{red}, \mathrm{Sp}}$ of the main spindle:

$\ddot{\varphi}=\frac{(1-e) \cdot P_{c}}{2 \cdot \pi \cdot \overline{n_{z y k}} \cdot J_{r e d, S p}}$

The spindle accelerates and decelerates around the predefined rotational speeds according to Fig. 7. The rotational speed range, by which the axes are accelerated or decelerated, should be $\pm 10 \%$ of the rotational speeds $\bar{n}$.

\section{Motion sequence: example}

Figure 8 illustrates the spindle speed and the linear axis travel as a function of time, consisting of four motion cycles. The motion sequence is carried out on the five axis machine tool HEC630 available at the Fraunhofer Institute for Machine Tools and Forming Technology IWU in Chemnitz. For the first investigations only the linear axes and the main spindle are used to heat up the machine tool. The power values for this example are based on a representative milling process. The duration of the motion cycle in the cutting feed is $42.5 \mathrm{~s}$, in rapid traverse only $20.8 \mathrm{~s}$. The first and second motion cycles are implemented in the cutting feed, the third in rapid traverse, and the fourth again in the cutting feed. Thus, we obtain a total duration of $148.3 \mathrm{~s}$ for the motion sequence. During this time, the main spindle is accelerated by two rotational speed levels. The first rotational speed level corresponds to $65 \%$ of the nominal rotational speed, the second to $85 \%$. Each rotational speed level is valid for a period of $1 \mathrm{~min}$.

\section{Outcomes and outlook}

On the examined machine tool the duration of the investigation up to thermal steady-state lasted from 6 to $10 \mathrm{~h}$. The parameters for the motion sequence were set based on the power data of a representative manufacturing process for this machine tool. A MATLAB program was created to provide the path-time profile in an automated manner. In the MATLAB program, the process parameters and the technical data of the feed axes, as well as of the main spindle, are specified. The investigations were focused on the repeatability of the test process and the analysis, as well as the elimination of non-thermal influences. Figure 9 shows the test workpiece in machine tool HEC630 and measuring results for the thermally induced displacements of the linear axes. The $\mathrm{X}$ and $\mathrm{Y}$ axis are arranged on the tool side, the $\mathrm{Z}$ axis and both rotational axes $\mathrm{A}$ and $\mathrm{B}$ are arranged on the workpiece side. On the left side are the results for a manufacturing time of $8 \mathrm{~h}$, on the right side the results over $10 \mathrm{~h}$. A thermal steady state is visible for the $\mathrm{x}$ and $y$-axis. The rapid increase of the $z$-displacement is caused by the elongation of the main spindle. However, then a decline in the displacement occurs by the very slow displacement of the whole geometrical machine structure. Even after $8 \mathrm{~h}$ is not thermally stable state recognizable. Therefore, the heating time was increased to $10 \mathrm{~h}$. The results are on the right side. A decline is still visible, but with only small changes. In the results, there are also differences in the maximum displacement in Z-direction between both results. The cause has not yet been determined. Additional measurements are made under the same boundary conditions for a statistical validation of the results. In further studies motion sequences for different machine tools are generated. The focus is the variation of the performance data, the motion profile and the number of the simultaneously moving axes. So that different load case can be defined and used to warm up the machine tool. The results of the workpiece can used to show the effectiveness
Fig. 8 Axis travels and spindle rotational speed as a function of time

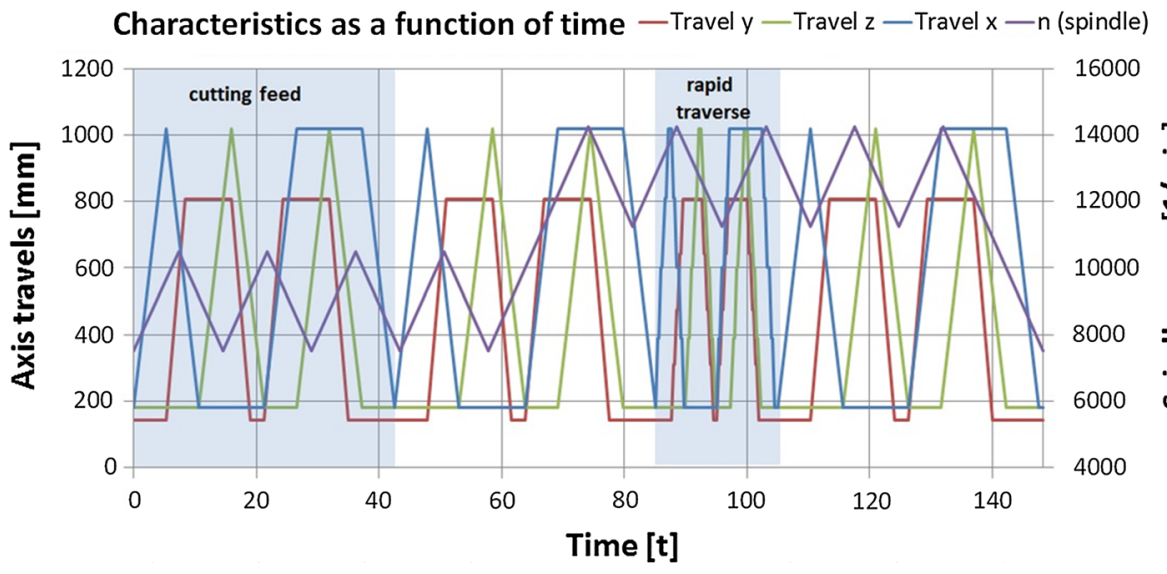


Fig. 9 Measuring results obtained for the test workpiece at the HEC630 machining centre

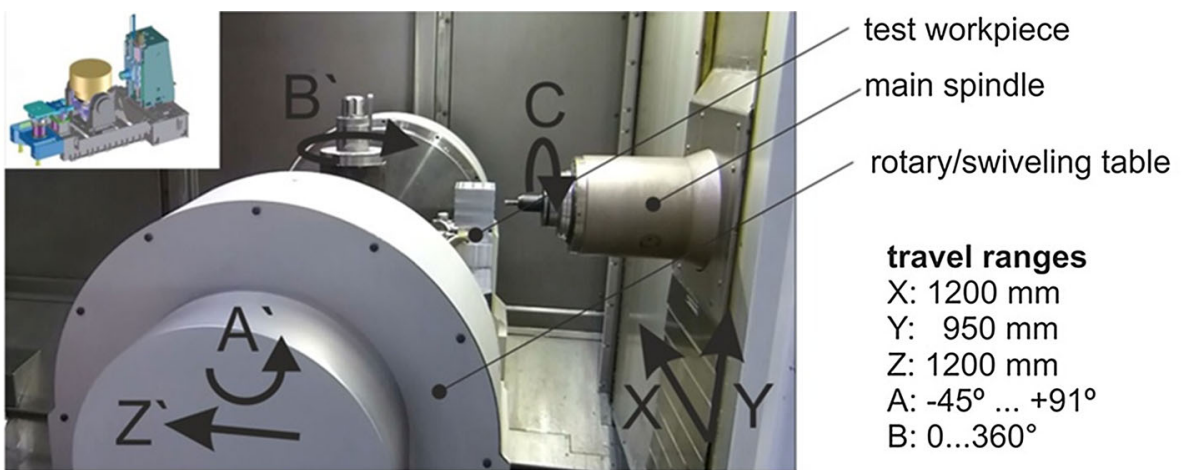

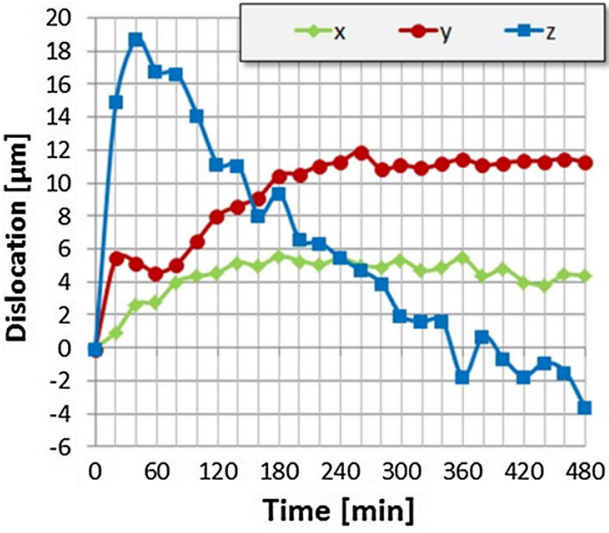

Time of manufacturing $\sim 8 \mathrm{~h}$

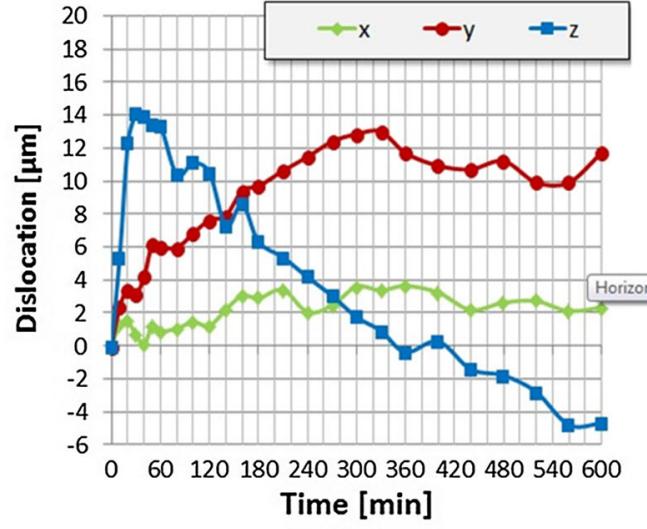

Time of manufacturing $\sim 10 \mathrm{~h}$ of the developed correction and compensation techniques in the CRC "Transregio96". Under the same thermal load one side of the workpiece will show the results of investigations with the integrated technique, the other side without the technique.

Acknowledgements The activities executed in the project were financed by the German research Association DFG within the scope of the Collaborative Research Centre CRC "Transregio 96" on "Thermo-energetic design of machine tools". The authors are grateful to the DFG for funding. The authors also thank the Fraunhofer Institute for Machine Tools and Forming Technology IWU in Chemnitz, the Starrag-Heckert company and the Institute for Manufacturing Engineering of the TU Dresden for their support in the execution of explorations and experiments.

Open Access This article is distributed under the terms of the Creative Commons Attribution 4.0 International License (http://crea tivecommons.org/licenses/by/4.0/), which permits unrestricted use, distribution, and reproduction in any medium, provided you give appropriate credit to the original author(s) and the source, provide a link to the Creative Commons license, and indicate if changes were made.

\section{References}

1. Neidhardt L, Höfer H, Wiemer H (2014) Prüfwerkstück zum Nachweis von thermisch bedingten Verlagerungen an
Fräsmaschinen-Konzept und erste Erfahrungen. ZWF 109(11):814-818

2. Degener W, Lutze H, Smejkal E (2009) Spanende Formung, vol 16. Hanser Verlag, München

3. International Organization for Standardization (2007) ISO 230-3: test code for machine tools - Part 3: Determination of thermal effects. Geneva, Switzerland

4. International Organization for Standardization (2007) ISO 10791-10: test conditions for machining centers - Part10: Evaluation of thermal distortions. Geneva, Switzerland

5. International Organization for Standardization (2004) ISO 13041-8: test conditions for numerically controlled turning machines and turning centers - Part8: Evaluation of thermal distortions. Geneva, Switzerland

6. Deutsches Institut für Normung (1990) DIN V 8602 Teil 1: Verhalten von Werkzeugmaschinen unter statischer und thermischer Beanspruchung: Allgemeine Regeln für die Prüfung von Fräsmaschinen

7. Weck M, Brecher C (2013) Werkzeugmaschinen 7: Messtechnische Untersuchung und Beurteilung, Dynamische Stabilität, vol 7. Springer, Berlin, p 423

8. Weck M, Brecher C (2013) Werkzeugmaschinen 7: Messtechnische Untersuchung und Beurteilung, Dynamische Stabilität, vol 7. Springer, Berlin, pp 185-186

9. VDI-Gesellschaft (1986) Zurückgezogen. VDI 2851 Blatt 3: Numerisch gesteuerte Arbeitsmaschinen: Beurteilung von Fräsmaschinen und Bearbeitungszentren durch Einfachprüfwerkstücke. VDI Verlag, Düsseldorf

10. International Organization for Standardization (2014) ISO 10791-7: test conditions for machining centers - Part 7: Accuracy of finished test pieces. Geneva, Switzerland 
11. VDI-Gesellschaft (1977) VDI 3443: Statistische Prüfung der Arbeitsgenauigkeit von Fräsmaschinen. VDI Verlag, Düsseldorf

12. VDI-Gesellschaft/NC-Gesellschaft (2013) VDI 5211 part 1 draft: testing guidelines and testing workpieces for high speed cutting (HSC): milling machines and machining centres for 3-axis machining. Beuth Verlag, Düsseldorf

13. VDI-Gesellschaft/NC-Gesellschaft (2013) VDI 5211 part 2 draft: testing guidelines and testing workpieces for high speed cutting (HSC): milling machines and machining centres for 5-axis simultaneous milling. Beuth Verlag, Düsseldorf

14. VDI-Gesellschaft/NC-Gesellschaft (2012) VDI 5211 part 3 draft: test work pieces for machine tools: milling: micromachining. Beuth Verlag, Düsseldorf

15. Gebhardt M, Knapp W, Wegener K (2012) 5-axis test-pieceinfluence of machining position. In: Proceedings of the MTTRF 2012 annual meeting, Iga City, Japan, pp 299-304

16. Su Z, Wang L (2015) Latest development of a new standard for the testing of five-axis machine tools using an S-shaped test piece. Proc Inst Mech Eng Part B J Eng Manuf 229(7):1221-1228
17. Keaveney S, Connolly P, Ahearne E, Byrne G (2014) Investigation of a multi-cone variant of the standard cone frustum test for 5-axis machine tool. In: 6th CIRP international conference on high performance cutting (procedia CIRP), vol 14, pp 317-322, Berkeley, CA, USA

18. Westermann HH, Kafara M, Steinhilper R (2015) Development of a reference part for the evaluation of energy efficiency in milling operations. In: 12th global conference on sustainable manufacturing (procedia CIRP), vol 26, pp 521-526, Johor Bahru, Malaysia

19. Brecher C, Haber D (2013) Thermisch bedingte Verlagerungen von Werkzeugmaschinen. ZWF 108(7-8):483-486

20. Ibaraki S, Ota Y (2014) A machine test to calibrate rotary axis error motions of five-axis machine tools and its application to thermal deformations test. Int J Mach Tools Manuf 86:81-88

21. Wiessner M, Gebhardt M, Knapp W, Wegener K (2014) Test piece for visualization of thermally induced deviations on fiveaxis machine tools. In: EUSPEN—special interest group meeting: thermal issues, Zürich, Schweiz 